This is the post-print version of the article.

The final article - and the full citation is: Michael Henderson, Neil Selwyn, Glenn Finger \& Rachel Aston

(2015). Students' everyday engagement with digital technology in university: exploring patterns of use and 'usefulness'. J ournal of Higher Education Policy and Management, 37(3), 308-319. DOI:

http:/ / dx. doi. org/ 10.1080/ 1360080X. 2015. 1034424

\title{
Students' everyday engagement with digital technology in university: exploring patterns of use and 'usefulness'
}

\author{
Michael Henderson \\ Faculty of Education \\ Monash University \\ michael.henderson@monash.edu
}

Neil Selwyn

Faculty of Education

Monash University

neil.selwyn@monash.edu

\author{
Glenn Finger \\ Arts, Education and Law Group \\ Griffith University \\ G.Finger@griffith.edu.au
}

Rachel Aston

Faculty of Education

Monash University

rachel.aston@monash.edu

\begin{abstract}
The much-discussed potential of 'technology-enhanced learning' is not always apparent in the day-to-day use of digital technology throughout higher education. Against this background, the present paper considers the digital devices and resources that students engage most frequently with during their university studies, what these technologies are being used for, and perceptions of 'usefulness' attached to these uses. The paper draws upon data gathered from a survey of undergraduate students $(n=1658)$ across two Australian universities. Having explored a variety of factors shaping student engagement with digital technology within these university settings, the paper considers how ongoing discussions about digital technology and higher education might better balance enthusiasms for the 'state of the art' (i.e. what we know might be achieved through technology-enabled learning) with an acknowledgement of the 'state of the actual' (i.e. the realities of technology use within contemporary university contexts).
\end{abstract}

Keywords: university, students, digital technology, internet, usefulness, technology-enabled learning

\section{Introduction}

Digital technology is now woven deeply into the fabric of university teaching and learning ranging from the institutional provision of 'learning management systems', e-journals and plagiarism detection tools, to the widespread individual use of word-processing, email, 
This is the post-print version of the article.

The final article - and the full citation is: Michael Henderson, Neil Selwyn, Glenn Finger \& Rachel Aston

(2015). Students' everyday engagement with digital technology in university: exploring patterns of use and 'usefulness'. J ournal of Higher Education Policy and Management, 37(3), 308-319. DOI:

http:// dx. doi. org/ 10.1080/ 1360080X. 2015. 1034424

Google and Wikipedia. On one hand, students' use of digital technology is now a wholly unremarkable feature of contemporary higher education; an expected part of the routines of academic study and wider campus life. On the other hand, digital technology continues to be talked about (especially by those not involved immediately in university teaching and learning) in portentous terms of systematic change and reform. Some commentators see university teaching and learning as having already been 'enhanced' and even 'transformed' by the flexibility and adaptability of digital education (e.g. Beetham \& Sharpe, 2013). Others see universities struggling to keep pace with the 'disruptive' nature of new technologies and the demands of cohorts of ever more 'digitally native' students (Losh, 2014). Either way, the over-riding sense is of fundamental re-alignment and reform of university teaching and learning along digital lines.

As might be expected, there is growing evidence to suggest that students' actual technology use in higher education settings is considerably more constrained and compromised than such rhetoric might suggest. Far from being 'digital natives', university students comprise a wide spectrum of digital competence, aptitudes, interests and dispositions that range from 'power users' to 'basic users' (Kennedy et al., 2010; Eynon \& Malmberg, 2012). Research studies report varying levels of digital confidence and skills amongst students, alongside the willingness of many to conform their university-related technology use around the requirements of courses and institutions (Jones, 2012). Detailed observations of students' technology-based practices suggest them to be sometimes of little academic relevance (Paretta \& Catalano, 2013), and often shaped by material, temporal and spatial boundaries (Gourlay \& Oliver, 2013). While acknowledged rarely in discussions of the 'Digital Campus' or 'Twenty-First Century University' (see, for example, Barber et al., 2013; Marcum, 2014), students' engagement with digital technology is clearly varied, variable and shaped by an array of contextual factors. To appropriate the title of Danah Boyd's (2014) recent analysis of young people’s use of digital technology in general: 'It's Complicated'.

As a contribution to the emerging literature on the complexity of student (non) use of digital technology, this paper addresses the simple questions of how students are most commonly engaging with digital technologies during their university studies, and the ways in which different forms of digital engagement are being perceived as useful. Across these two broad areas of questioning particular interest is paid to issues of patterning; specifically, in terms of commonalities and differences between groups of students (e.g. subject disciplines, age and stage, gender, educational attainment, cultural and linguistic diversity and so on).

\section{Research methods}

These questions are addressed through an analysis of survey data collected as part of research funded by the Australian Government Office of Learning and Teaching. Data were collected during the 2014 academic year from students of two large Australian universities situated in the southeast and northeast of Australia. These universities were of similar size; each with multiple campuses providing a breadth of courses at undergraduate and postgraduate levels with academic and vocational orientations. Undergraduate students in both institutions were invited to complete an online questionnaire containing items investigating their engagement with digital technologies. The self-selecting sample of those students who chose to respond consisted of 1658 students with an age range of 17 to 66 (mean age=22.5, SD=6.9). As can 
This is the post-print version of the article.

The final article - and the full citation is: Michael Henderson, Neil Selwyn, Glenn Finger \& Rachel Aston (2015). Students' everyday engagement with digital technology in university: exploring patterns of use and 'usefulness'. J ournal of Higher Education Policy and Management, 37(3), 308-319. DOI:

be seen in Table 1, the sample was within expectation in terms of academic performance, mode of study, domicile status and cultural and linguistic diversity, although there was an over-representation of female students (66.6 per cent in this study compared with 55.8 per cent nationally according to the Aust Gov’t Dept Industry, 2012), full-time students (92.9 per cent versus 70.3 per cent nationally) and those taking medicine (over-representation by 6 per cent), business (under-representation by 10 per cent) and science subjects (overrepresentation by 6 per cent).

Table 1

Survey respondents by individual characteristics $(n=1658)$

\begin{tabular}{|c|c|c|c|}
\hline \multirow{3}{*}{ Gender } & & $\mathrm{n}$ & $\%$ \\
\hline & Female & 945 & 66.6 \\
\hline & Male & 473 & 33.4 \\
\hline \multirow[t]{2}{*}{ University } & University A (SE Australia) & 1250 & 75.4 \\
\hline & University B (NE Australia) & 408 & 24.6 \\
\hline \multirow[t]{4}{*}{ Year of study } & First & 627 & 37.9 \\
\hline & Second & 395 & 23.9 \\
\hline & Third & 347 & 21.0 \\
\hline & Fourth (and above) & 287 & 17.3 \\
\hline \multirow[t]{9}{*}{ Subject area } & Medicine (and allied subjects) & 366 & 22.1 \\
\hline & Sciences (physical and biological) & 245 & 14.8 \\
\hline & Engineering, computer science \& maths & 181 & 10.9 \\
\hline & Business & 275 & 16.6 \\
\hline & Social sciences, economics and politics & 132 & 8.0 \\
\hline & Law & 122 & 7.4 \\
\hline & Humanities, languages and library studies & 113 & 6.8 \\
\hline & Creative arts and design & 60 & 3.6 \\
\hline & Education & 162 & 9.8 \\
\hline \multirow[t]{2}{*}{ Mode of study } & Full-time study & 1321 & 92.9 \\
\hline & Part-time study & 101 & 7.1 \\
\hline \multirow[t]{2}{*}{ Age group } & Mature aged (i.e. aged 21 years or more at entry) & 288 & 20.5 \\
\hline & Younger (i.e. aged 20 years or less at entry) & 1119 & 79.5 \\
\hline \multirow[t]{4}{*}{ Academic performance } & High distinction & 236 & 17.1 \\
\hline & Distinction & 643 & 46.6 \\
\hline & Credit & 410 & 29.7 \\
\hline & Pass (or lower) & 91 & 6.6 \\
\hline \multirow[t]{2}{*}{ Domicile status } & Domestic students & 1258 & 88.8 \\
\hline & International students & 159 & 11.2 \\
\hline \multirow[t]{2}{*}{ Employment status } & Working in paid employment while studying & 916 & 64.4 \\
\hline & Not working in paid employment while studying & 506 & 35.6 \\
\hline \multirow[t]{2}{*}{ First language } & English as first language & 1195 & 84.3 \\
\hline & Language other than English as a first language & 222 & 15.7 \\
\hline
\end{tabular}


This is the post-print version of the article.

The final article - and the full citation is: Michael Henderson, Neil Selwyn, Glenn Finger \& Rachel Aston

(2015). Students' everyday engagement with digital technology in university: exploring patterns of use and 'usefulness'. J ournal of Higher Education Policy and Management, 37(3), 308-319. DOI:

http:/ / dx. doi. org/ 10.1080/ 1360080X. 2015. 1034424

\begin{tabular}{llcc} 
Disability & Student with no declared disability & 1355 & 95.7 \\
& Student with declared disability & 61 & 4.3 \\
& & & \\
Indigenous background & Aboriginal and/or Torres Strait Islander origin & 11 & 0.8 \\
& Not of Aboriginal and/or Torres Strait Islander origin & 1391 & 99.2 \\
\hline
\end{tabular}

Note. Some totals do not add up to 1658 due to differing completion rates for each item.

This paper examines survey data relating to students' reported types and levels of digital technology use relating to their university studies, as well as perceptions relating to the usefulness of this technology use. Analysis of the survey data was conducted in a relatively straightforward manner, acknowledging the limitations of the self-selecting, non-randomized nature of the sample and the lack of complete measurement of all cases in the selected sample (de Vaus, 2002; Gorard, 2014). Thus, in light of the growing trend for the 'appropriate use of numbers' within educational research, the analysis of the data set therefore takes the form of frequencies and cross-tabulations (see also Gorard, 2006). Similarly, analysis of the textual data arising from the open-ended items related to perceived usefulness took the form of relatively straightforward thematic analysis. This involved initial readings of all responses to the open-ended survey items to gain an overall sense of the data. These data were then read again and 'open-coded' to produce an initial code list until, in the opinion of the research team, analysis had reached theoretical saturation. Although some codes were adapted which directly used the language of the respondents the majority were researcher-led and analytic. From this basis the data were then coded in terms of categories identified with the initial code list directly related to the aims of the study.

\section{Results}

\section{Students' reported uses of digital technologies}

As can be seen in Figure 1, students reported using a variety of digital devices. Nearly every respondent reported using a personally owned laptop/ desktop computer, with nearly all of these respondents (95.4 per cent) making use of this device for their university studies. In contrast, nearly 40 per cent of respondents were making no use of computers provided by/located in the university. 
This is the post-print version of the article.

The final article - and the full citation is: Michael Henderson, Neil Selwyn, Glenn Finger \& Rachel Aston (2015). Students' everyday engagement with digital technology in university: exploring patterns of use and 'usefulness'. J ournal of Higher Education Policy and Management, 37(3), 308-319. DOI: http:/ / dx. doi. org/ 10.1080/ 1360080X. 2015. 1034424

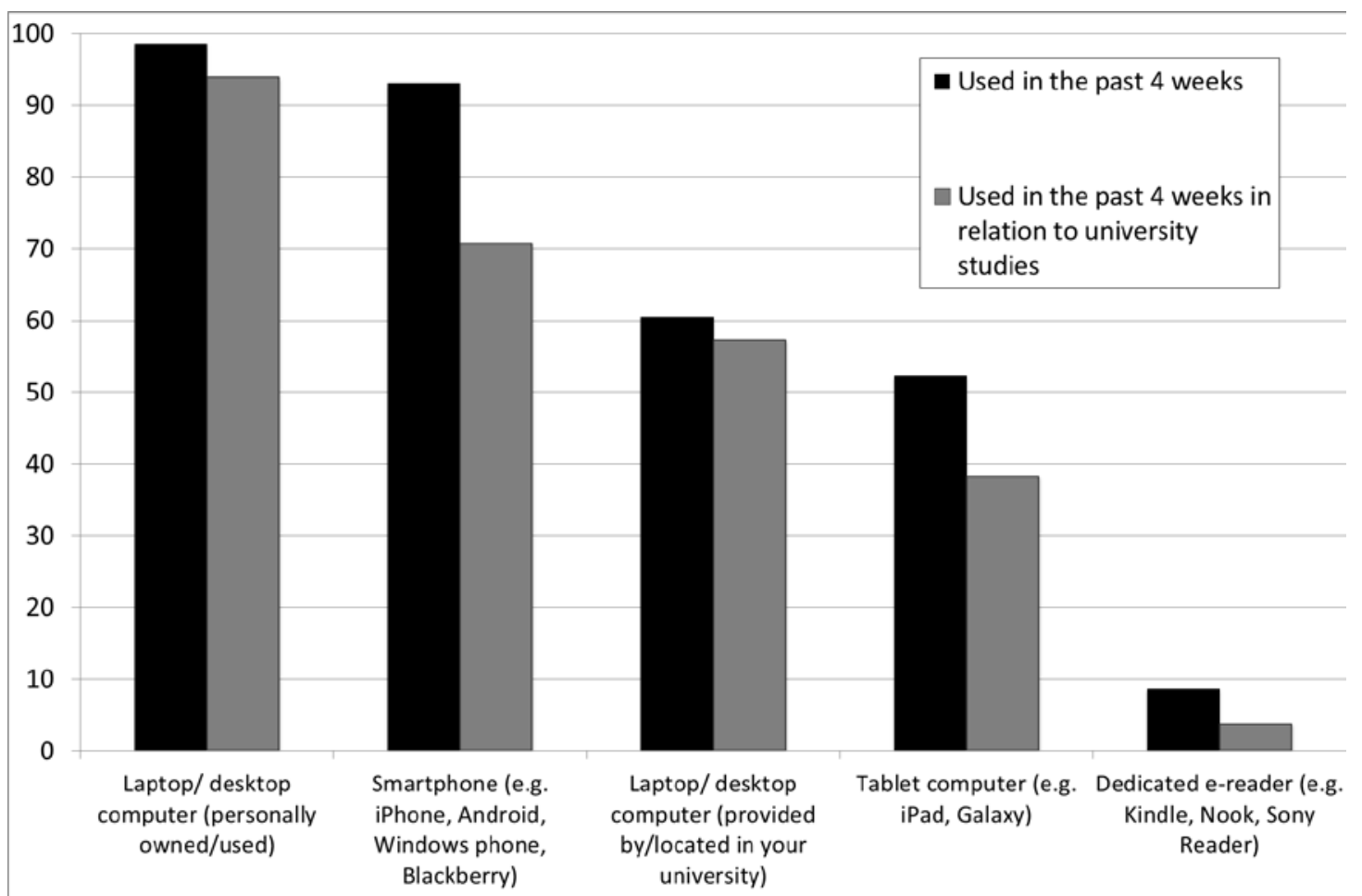

Figure 1. Students’ reported use of digital devices during the previous four weeks.

The survey also suggested that smartphones were being used increasingly to support students’ academic studies; especially amongst students studying on fulltime (82.8 per cent) as opposed to part-time (72.0 per cent) courses. Conversely, tablets/iPads were only being used by fewer students (52.3 per cent) with just over two-thirds of these students reporting making use of their tablet/iPad for university work. While (non)use of tablets was relatively comparable across the sample, academic use of tablets for university work was notably higher for international/overseas students (82.7 per cent) than for home/domestic students (72.6 per cent).

Of course, students' general levels of digital device use are of less importance than what these devices were being used for. Here the distinction can be made between 'official' and 'non-official' digital resources and practices. In terms of 'official' digital resources (i.e. those provided and/or mandated by universities), the survey data confirmed the prominence of learning management systems and online library resources (see Table 2). These data also highlight the growing use of e-books and e-textbooks (reported by 83.9 per cent). Use of all these 'official' resources was remarkably consistent throughout the sample, regardless of subject discipline, level of study or other individual characteristics measured in the survey.

Table 2

Students' use of 'official' digital technology resources in relation to their university studies, and the perceived usefulness of these in enhancing learning.

\begin{tabular}{lccc}
\hline & $\begin{array}{c}\text { Used as part } \\
\text { of university } \\
\text { studies }\end{array}$ & $\begin{array}{c}\text { Reported as } \\
\text { 'Useful' or } \\
\text { 'Very Useful' }\end{array}$ & $\begin{array}{c}\text { Reported as } \\
\text { Learning Management System }\end{array}$ \\
\cline { 2 - 4 } & 99.8 & 94.8 & 57.8 \\
\hline
\end{tabular}


This is the post-print version of the article.

The final article - and the full citation is: Michael Henderson, Neil Selwyn, Glenn Finger \& Rachel Aston (2015). Students' everyday engagement with digital technology in university: exploring patterns of use and 'usefulness'. J ournal of Higher Education Policy and Management, 37(3), 308-319. DOI: http:/ / dx. doi. org/ 10.1080/ 1360080X. 2015. 1034424

\begin{tabular}{llll}
\hline Use library online resources to find information & 97.2 & 93.7 & 66.2 \\
Library website & 98.2 & 83.4 & 40.2 \\
Other university websites & 84.0 & 52.3 & 11.9 \\
E-books or e-textbooks & 83.9 & 76.8 & 37.6 \\
Software specific to my study area & 56.9 & 64.3 & 28.4 \\
Simulations or educational games & 57.2 & 52.1 & 18.6 \\
\hline
\end{tabular}

Note. Data are percentage of sample responding to each survey item.

More variation was apparent, however, with regards to use of what could be classed as 'nonofficial' digital resources (i.e. resources that were not part of university-provided systems and services). As can be seen in Table 3, large proportions of students reported making use of general internet search engines (such as Google) and specialized academic search services (such as Google Scholar, Web of Science and so on). Other prevalent practices included viewing subject-related videos on video sharing websites such as YouTube, communicating and/or collaborating with other students through Facebook and other social networks, as well as finding information related to their university studies on Wikipedia.

Table 3

Students' use of 'non-official' digital technology resources in relation to their university studies, and the perceived usefulness of these in enhancing learning.

\begin{tabular}{|c|c|c|c|}
\hline & $\begin{array}{l}\text { Used as part } \\
\text { of university } \\
\text { studies }\end{array}$ & $\begin{array}{l}\text { Reported as } \\
\text { 'Useful' or } \\
\text { 'Very Useful' }\end{array}$ & $\begin{array}{l}\text { Reported as } \\
\text { 'Very Useful' }\end{array}$ \\
\hline Use internet search engines to find information & 99.4 & 96.9 & 68.3 \\
\hline $\begin{array}{l}\text { Search for papers/journals on non-university } \\
\text { provided scholarly websites }\end{array}$ & 91.8 & 81.5 & 45.7 \\
\hline $\begin{array}{l}\text { Watch or listen to audio recordings or videos } \\
\text { about your subject/ discipline (e.g. YouTube, } \\
\text { Vimeo) }\end{array}$ & 92.8 & 84.4 & 40.6 \\
\hline $\begin{array}{l}\text { Use social networking sites for working with } \\
\text { other students on your courses (e.g. Facebook) }\end{array}$ & 89.0 & 74.8 & 36.5 \\
\hline Finding information through Wikipedia & 87.5 & 65.3 & 24.0 \\
\hline Web-based citation/bibliography tools & 72.3 & 63.3 & 31.3 \\
\hline $\begin{array}{l}\text { Use web-based document for working with other } \\
\text { students on your courses (e.g. Google Docs, } \\
\text { Wikispaces }\end{array}$ & 73.6 & 71.5 & 33.9 \\
\hline $\begin{array}{l}\text { Freely available courses and educational content } \\
\text { from outside of my university (e.g. i-Tunes U, } \\
\text { Khan Academy, OERs) }\end{array}$ & 65.6 & 64.6 & 29.8 \\
\hline Twitter & 48.1 & 14.5 & 3.5 \\
\hline
\end{tabular}

Note. Data are percentage of sample responding to each survey item.

The extent of students' engagement in these non-official practices differed across the sample. For example, collaborating with other students through Facebook was more prevalent for fulltime (90.2 per cent) as opposed to part-time (73.4 per cent) students, and for younger (91.7 per cent) rather than mature aged (78.3 per cent) students. Recurring differences were also found in terms of students' domiciled status, with international students notably more 
This is the post-print version of the article.

The final article - and the full citation is: Michael Henderson, Neil Selwyn, Glenn Finger \& Rachel Aston

(2015). Students' everyday engagement with digital technology in university: exploring patterns of use and 'usefulness'. J ournal of Higher Education Policy and Management, 37(3), 308-319. DOI:

http:/ / dx. doi. org/ 10.1080/ 1360080X. 2015. 1034424

likely to be users of a range of 'non-official' applications in comparison to domestic students. This included looking for information on Wikipedia (95.9 per cent of international as opposed to 86.3 per cent of domestic students); the use of free and 'open' external resources (72.5 per cent of international as opposed to 64.5 per cent of domestic students); and collaborative Wiki/Google docs (87.8 percent, 71.7 per cent). Students living on-campus were also more likely to use collaborative Wiki/Google docs than students who lived offcampus (80.3 percent, 72.4 per cent). However, these differences in technology use are likely to be entwined since international students in this survey constitute a quarter of those who live on campus (35.8 per cent of international, $n=56$; 12.5 per cent of domestic, $n=157$ ).

There were also notable differences in the use of technology according to gender and discipline. Again, these characteristics may sometimes be entwined since some disciplines have higher proportions of females or males. The dataset precludes reliable multivariate analysis to further explore this issue, however future project work is planned to address this. Nevertheless, the differences in use, and usefulness, according to gender and discipline serve to reveal interesting facets of the undergraduate technology landscape. Male students were more likely to use Facebook in support of peer collaboration (93.0 per cent) than female students (86.9 per cent). Indeed, male students were significantly more likely to be users of a range of 'non-official' applications in comparison to their female counterparts. For example, looking for information on Wikipedia was notably more likely to be reported as being used by male students (95.0 per cent) than females (83.5 per cent). Other gendered differences included the use of freely available 'open' educational resources (75.1 per cent of males, as opposed to 60.7 per cent of females); and working with other students through collaborative Wiki spaces such as Google Docs (78.8 percent, 70.9 per cent). However, as noted earlier, these gendered differences were sometimes entwined with other characteristics. To take students' use of Wikipedia as an example, 95.3 per cent of respondents studying Engineering/Computer Science/Maths subjects (comprising 79.1 per cent males) reported using Wikipedia, this was the case for only 72.6 per cent of students studying Education subjects (comprising 86.7 per cent females).

The use of Wikipedia in particular was shown to not only differ according to gender, discipline, and students' domiciled status, but also was also found to increase throughout the years of study: from 83.8 per cent of students in their first year of study; to 87.2 per cent of second year; 88.7 per cent of third years; and 94.2 per cent of students studying in their fourth/final year. However, the frequency of Wikipedia, and the other technologies described above, need to also be considered in light of undergraduate students perceived usefulness of these technologies for their university studies.

\section{Students' perceived usefulness of digital technologies}

We also need to consider the usefulness of these digital resources and practices. As tables two and three also show, the digital technologies covered by the survey were reported to be of varying usefulness. Amongst the most 'useful' digital resources was using general internet search engines (such as Google) to find information, using library online resources to find information, and making use of university Learning Management Systems. Also rated highly was making use of university library resources, alongside the use of academic search services such as Google Scholar and Web of Knowledge, and viewing subject-related videos on content sharing websites such as YouTube. 
This is the post-print version of the article.

The final article - and the full citation is: Michael Henderson, Neil Selwyn, Glenn Finger \& Rachel Aston

(2015). Students' everyday engagement with digital technology in university: exploring patterns of use and 'usefulness'. J ournal of Higher Education Policy and Management, 37(3), 308-319. DOI:

http:/ / dx. doi. org/ 10.1080/ 1360080X. 2015. 1034424

This perceived usefulness varied across the survey sample. For example, collaborating with classmates through Facebook was perceived as more useful by fulltime (76.0 per cent) as opposed to part-time (56.5 per cent) students. In contrast, part-time students were more likely to see the university library websites (89.1 per cent) and bibliographic tools (72.1 per cent) as 'useful' when compared to their full-time counterparts (82.9 per cent and 62.6 per cent respectively). University library websites were more likely to be seen as useful by mature aged (91.3 per cent) rather than younger (81.3 per cent) students. Persistent differences were also found between domestic and international students. International students were significantly more likely to report looking for information on Wikipedia as 'useful' in comparison to domestic students (78.9 per cent of international, as opposed to 63.1 per cent of domestic students). Conversely, domestic students were more likely to perceive the use of freely available courses and open educational content from outside of their university as useful (65.4 per cent of domestic, as opposed to 58.4 per cent of international students); and using Facebook to communication and/or collaborate with other students (75.7 per cent, 68.1 per cent).

Wikipedia again offers a good example of the interrelated nature of some of these differences. Looking for information on Wikipedia was perceived to be more useful by male (76.7) as opposed to female (58.4 per cent) students. Again, these differences are related partly to subject-related differences, with 78.1 per cent of respondents studying Engineering, Computer Science \& Maths subjects reporting Wikipedia as useful as opposed to 34.5 of students studying Education subjects. Furthermore, Wikipedia use was also perceived as more useful by mature aged (71.2 per cent) rather than younger (63 per cent) students; and students not working in paid employment while studying (72.0 per cent) as compared to students working in paid employment (61.5 per cent).

\section{The nature of the use and usefulness of students' digital practices}

Finally, the survey also asked respondents to nominate and justify the digital technologies that they found to be 'most useful' during their university studies. From the 4594 nominated examples, eleven distinct digital practices were identified and coded. These data provide further insight into what students were using digital technologies for, and what meanings were being attached to these practices. As can be seen in Table 4, the most prominent practices related to the logistics of university study: organizing schedules and fulfilling course requirements; being able to engage with university studies on a 'remote' and/or mobile basis; and the broad issue of managing time and time-saving.

Tellingly, practices explicitly related to learning were reported less frequently. The most prominent learning-related practice was using digital technologies to 'research information'. 'Reviewing, replaying and revising' digitally recorded learning materials - most notably the viewing and listening of lecture recordings - was also a prominently reported practice. While less frequently reported, the practice of 'looking elsewhere' for supplementary materials to corroborate or clarify what had been learnt at university was also a recurring theme, as was the capacity of digital technologies to allow students to engage with information in more 'visual' forms.

Table 4. 
This is the post-print version of the article.

The final article - and the full citation is: Michael Henderson, Neil Selwyn, Glenn Finger \& Rachel Aston

(2015). Students' everyday engagement with digital technology in university: exploring patterns of use and 'usefulness'. J ournal of Higher Education Policy and Management, 37(3), 308-319. DOI:

http:/ / dx. doi. org/ 10.1080/ 1360080X. 2015. 1034424

Cited reasons for digital technology usefulness in relation to students' university studies

$\begin{array}{lll}\text { Practice } & \text { Description } & \begin{array}{l}\text { Digital devices/practices } \\ \text { most cited in relation to } \\ \text { this factor }\end{array}\end{array}$

\begin{tabular}{ll}
\hline $\begin{array}{l}\text { Organizing \& } \\
\text { managing the }\end{array}$ & $\begin{array}{l}\text { Managing schedules, timetables, } \\
\text { fulfilling deadlines and course }\end{array}$ \\
logistics of & requirements, 'keeping in the loop' re. \\
studying & university and course information and \\
& news.
\end{tabular}

Flexibility of Flexibility of location, ability to engage

place \& location 'remotely' with academic work off-

Learning management

46.9

system as repository of

resources \& information.

campus, engaging at a distance and not

having to be 'present', being able to be

mobile, portability of university work

Time-saving Saving student time, quicker processes, more immediate outcomes, convenient scheduling of activities.

\section{Researching information}

\author{
Reviewing, \\ replaying \& \\ revising
}

Supporting basic tasks

\section{Communicating \& collaborating}

\section{Augmenting university learning materials

Seeing
information in
different ways

Cost saving

Gauging a sense of progress
Researching information for assignments; quantity and quality of information access

Catching up on missed material, repeating viewing of materials to improve understanding

'Easier' writing of assignments; 'easier' and 'helpful' information management and retrieval of resources

Asking questions and exchanging information; working with other students; sharing ideas; preparing group work.

Watching lectures, tutorials and talks from outside university; cross-checking and comparing with other sources; 'going elsewhere'.

Visualizing concepts through video, animation or annotations; allowing real-time lecturer demonstrations and 'board work' in lectures;

Saving money and expenditure

Identifying gaps in understanding and knowledge; seeing what other students think; being tested; receiving feedback
Library databases and library websites; Laptop computers.

processing; Library databases and library websites; Online assignment submission.

Library databases and library websites;

Lecture recordings

(audio/video) of university lectures.

Writing notes/ wordprocessing; General internet search engines (e.g. Google).

Facebook and other social networks; Google docs, wikis, collaborative documents.

Watching videos from sources outside university; Wikipedia

Watching videos from sources outside university.

E-readers, online journals and books

Clickers, live polls in 
This is the post-print version of the article.

The final article - and the full citation is: Michael Henderson, Neil Selwyn, Glenn Finger \& Rachel Aston

(2015). Students' everyday engagement with digital technology in university: exploring patterns of use and 'usefulness'. J ournal of Higher Education Policy and Management, 37(3), 308-319. DOI:

http:/ / dx. doi. org/ 10.1080/ 1360080X. 2015. 1034424

These 'most useful' practices were cited consistently across the sample, with little recurrent patterning between different groups. That said, differences were notable in a few instances. For example, 50.8 per cent of students following Medicine (and allied subjects) reported the benefits relating to organising and managing the logistics of their studies, as opposed to 35.0 per cent of students studying Creative Arts and Design subjects. In contrast, this benefit was reported most by students in their first year (53.4 per cent) and reported least by students in their fourth/final year of study (30.0 per cent). Benefits relating to organising and managing the logistics of study were more likely to be reported by students who were achieving higher grades; with a steady increase from students achieving 'Pass (or lower)' grades (36.3 per cent) to students achieving 'High Distinction’ (53.8 per cent) grades.

Elsewhere, the practice of 'reviewing/revising/replaying material' was most likely to be reported by students following Engineering/Computer Science/Maths (32.6 per cent) and Science subjects (33.1 per cent); and least likely by students in the Social Sciences (21.2 per cent) and Education subjects (17.3 per cent). Benefits related to saving time were most likely to be reported by Humanities students (43.4 per cent) and least likely by those studying Creative Arts and Design (18.3 per cent). Conversely, female students (31.4 per cent) were more likely to report the benefit of the benefit of 'supporting basic skills' than male students (20.9 per cent). Benefits relating to flexibility of place and location were more likely to be reported by part-time students (44.6 per cent) than full-time students (34.1 per cent).

\section{Discussion}

These data present a mixed picture of university students' engagements with digital technology. On one hand, these data show digital technology to be an essential element of university study. Use of one's own computer (and increasingly smartphone) is now a common means for all but a handful of students to conduct their university studies. As such, our data support the increasingly prevalent 'bring your own device' mentality. However, our data also rejects the expected corollary of a decline of the 'university computer' in the everyday student experience (see Figure 1) with over half of students using university computers for their studies. Through these devices, learning management systems, library websites and databases, and internet searching are now all integral to contemporary undergraduate studies. It is now difficult to imagine being a university student without these technologies.

Our data also highlighted the emerging trend for digital technologies being used to support the visualization of higher education. For example, the data confirm the widespread practice of engaging with teaching and learning materials in video form. Alongside recordings of their own university lectures, many students were also turning to video sharing websites such as YouTube to find external video content to supplement their studies. Alongside this were the 'visual' benefits stemming from the use of animations, annotated materials, and the 'realtime' writing, sketching and drawing by lecturers in classes. All of these digital technologies were reported as allowing students to 'visualise' concepts and 'see information in a different way'. This clearly marks an additional way that digital technologies are finding a place in the everyday practices of undergraduate life. 
This is the post-print version of the article.

The final article - and the full citation is: Michael Henderson, Neil Selwyn, Glenn Finger \& Rachel Aston

(2015). Students' everyday engagement with digital technology in university: exploring patterns of use and 'usefulness'. J ournal of Higher Education Policy and Management, 37(3), 308-319. DOI:

http:// dx. doi. org/ 10.1080/ 1360080X. 2015. 1034424

On the other hand, the take-up of many other digital technologies appears to be more varied and inconsistent. Tellingly, these include a number of technologies that are often presumed to be integral to the contemporary 'digital native' student experience. For example, notwithstanding their high public profile, iPads and other tablet computers did not appear to be core academic tools for the majority of students. In addition, while Facebook was clearly established as a communication tool for this generation of students, other 'big name' social media were less prevalent. For example, Twitter was not reported as a prevalent part of university studies; while nearly half the sample reported trying to use it for academic purposes, only 14.5 per cent of those students found it 'useful' or 'very useful'. Similarly, while the majority of students used social media sites such as YouTube, contrary to popular discourse it was for consumption rather than creation or participation practices. Also, students' use of Wikipedia was not the ubiquitous practice that is often assumed, with our data showing significant variations in students' use of Wikipedia as an information source for their academic work.

Indeed, our data suggest that students' engagements with many different aspects of digital technology continue to be patterned along distinct lines. While there were fewer differences than might have been expected across subject disciplines, year of study and between the two university institutions, the persistence of gender differences was notable. While linked in part to imbalances in the number of male and female students taking various subject disciplines, the persistence of gender as a shaping factor in students' digital engagement clearly demands further investigation. Also recurrent were differences between students in terms of the basis of their candidature: in particular, whether they were domestic or international; studying on a fulltime or part-time basis; and whether they were mature-aged or younger. Many of these differences could well be associated with the differing forms of engagement with higher education study that are experienced within these groups. While more investigation of these patterns is required, such differences highlight that digital technology use is not a ubiquitous (or even consistent) presence amongst what is a diverse and divergent current student population.

In making sense of these findings it is perhaps helpful to view student engagement with digital technologies from two different perspectives; what can be classed as student logistics and student learning. The logistical aspects of university study refer to the day-to-day 'work' of being a university student. In this sense, much of the engagement with digital technologies reported in this paper relates to students' pragmatic negotiation of their work, that is, the immediate demands of university study that continue to be centred on issues of assignments, grades and (non)attendance. Indeed, the digital technologies that were most prominent in our data were those that fit closely with the immediate logistical realities of student life, such as the pressures of: lecture attendance, class scheduling, participating in mandatory group activities, reserving library materials, conducting 'research' in the form of locating and retrieving documents, as well as producing and submitting assignments. Thus it is these aspects of higher education that come to the fore when students celebrate the 'usefulness' and 'helpfulness' of digital technology: as evinced in descriptions of technology helping students 'stay in the loop', making research 'easier' and generally managing and organizing their studies.

Alongside this logistical engagement with digital technology comes the use of digital technologies for learning. Here, much of how digital technologies were being used, and 
This is the post-print version of the article.

The final article - and the full citation is: Michael Henderson, Neil Selwyn, Glenn Finger \& Rachel Aston

(2015). Students' everyday engagement with digital technology in university: exploring patterns of use and 'usefulness'. J ournal of Higher Education Policy and Management, 37(3), 308-319. DOI:

http:// dx. doi. org/ 10.1080/ 1360080X. 2015. 1034424

perceived as being useful, appeared to be shaped by dominant university models of the 'transmission' of learning, rather than any more fluid, networked, connected or individuallydriven forms of learning. Regardless of subject specialization, academic achievement or year of study, technology-based learning appeared to take the primary forms of the passive reception of information and instruction, coupled with the largely individualised practices of researching and producing assignments. Our data suggest that digital technologies are allowing students to pursue these modes of learning in more convenient but not novel ways. The ability to watch and re-watch videos from around the world, or the ability to search vast online databases of scholarly literature are valued by students, and therefore presumably of benefit to them. Nevertheless, most of the dominant digital practices in the day-to-day lives of university students in our study were those that conform to (and reinforce) instructivist notions of content, knowledge, pedagogy and learning. If anything, then, these students' experiences of 'technology enhanced learning' can be described most accurately as involving the passive consumption of knowledge rather than more active practices.

\section{Conclusion}

So what might these findings mean for those involved and/or interested in the growing presence of digital technologies in university teaching and learning? Firstly, is the need to acknowledge and then work with the diversity and variety of ways in which undergraduate students are engaging with digital technology. Above all, this entails paying more attention to the bulk of rather mundane digital practices that are integral elements of students' actual experiences of digital higher education. Universities are clearly not facing cohorts of students making extensive and imaginative use of digital technology during their studies. While small numbers of our survey respondents did report participating in MOOCs, using Tumblr and generally confirming to the description of 'power users', far more appeared to fit the more prosaic categories of what Kennedy et al. (2010) term as 'ordinary users' or even 'basic users'. It is these students, therefore, that should form the starting point for discussions of developing digital technology within universities, rather than the imagined demands of largely non-existent cohorts of 'digital natives'. Secondly, is the need to pay closer attention to how these 'basic' levels of engagement are shaped as much by the contexts of higher education as by any individual traits, capabilities or attitudes amongst students themselves. Clearly, students' academic uses of technologies follow the largely restrictive expectations that continue to pervade higher education with regards to knowledge, the development of what constitutes knowledge and understanding, and what counts as undergraduate learning, study and scholarship.

Above all, then, these data point to the need for discussions of higher education and digital technology to focus more on the mundane realities of the present, rather than the spectacular possibilities of the near future. Enthusiasms for the 'state of the art' (i.e. what we know could be achieved through technology-enabled learning) will only be of use to universities when balanced with acknowledgement of the 'state of the actual' (i.e. the realities of technology use within contemporary university contexts). As our data suggest, students' practices have not dramatically changed despite availability of new technologies. Above all, this paper suggests that current discussions of technology and pedagogy need to be balanced by a renewed attention to the non-digital structures and contexts of higher education such as the content of syllabi, expectations of assessment and 'success', student difference, and 
This is the post-print version of the article.

The final article - and the full citation is: Michael Henderson, Neil Selwyn, Glenn Finger \& Rachel Aston (2015). Students' everyday engagement with digital technology in university: exploring patterns of use and 'usefulness'. J ournal of Higher Education Policy and Management, 37(3), 308-319. DOI:

http:/ / dx. doi.org/ 10.1080/ 1360080X. 2015. 1034424

assumptions of engagement and learning. If higher education is to be genuinely improved or even enhanced through digital technologies, then these are the discussions that need to come to the fore.

\section{Acknowledgement}

Support for this publication has been provided by the Australian Government Office for Learning and Teaching. The views expressed in this publication do not necessarily reflect the views of the Australian Government Office for Learning and Teaching

\section{References}

Barber, M., Donnelly, K. \& Rizvi, S. (2013). An avalanche is coming: higher education and the revolution ahead London, Institute for Public Policy Research

Beetham, H. \& Sharpe, R. (2013). Rethinking Pedagogy for a Digital Age. London, Routledge.

Boyd, D. (2014). It's complicated. Durham NC, Duke University Press

de Vaus, D. (2002). Analyzing social science data. London, Sage

Eynon, R. \& Malmberg, L. (2011). A typology of young people's internet use: implications for education. Computers and Education 56 (3), 585-595

Goodfellow, R. \& Lea, M. (2013). Literacy in the digital university. London: Routledge.

Gorard, S. (2006). Using everyday numbers effectively in research. London: Continuum

Gorard, S. (2014). The widespread abuse of statistics by researchers: what is the problem and what is the ethical way forward? Psychology of Education Review 38(1), 3-10.

Gourlay, L. \& Oliver, M. (2013). Beyond 'the social': digital literacies as sociomaterial practice in Goodfellow, R. and Lea, M. (eds) Literacy in the digital university: critical perspectives on learning, scholarship and technology London, Routledge (pp.79-94).

Jones C. (2012). Networked learning, stepping beyond the net generation and digital natives in Dirckinck-Holmfeld, L., Hodgson, V. and McConnell, D. (eds.) Exploring the theory, pedagogy and practice of networked learning' New York, Springer.

Kennedy, G., Judd, T., Dalgarno, B. \& Waycott, J. (2010). Beyond natives and immigrants: exploring types of net generation students. Journal of Computer Assisted Learning , 26(5), 332-343.

Losh, E. (2014). The war on learning. Cambridge MA, MIT Press.

Marcum, D. (2014). Technology to the rescue. New York NY, Ithaka S+R

Paretta, L., \& Catalano, A. (2013). What students really do in the library: an observational study. The Reference Librarian 54(2), 157-167

Selwyn, N. (2014). Digital technology and the contemporary university. London: Routledge. 